\title{
Analysis of the Current and Future Land Use/Land Cover Changes in Peri-Urban Areas of Dar es Salaam City, Tanzania using Remote Sensing and GIS Techniques
}

\author{
Erick T Mnyali $^{1^{*}}$ and Silvia F Materu ${ }^{2}$ \\ ${ }^{I}$ Department of Geography and Environmental Studies, College of Natural and Applied \\ Sciences, Sokoine University of Agriculture, PO Box 3038 Morogoro, Tanzania. \\ ${ }^{2}$ Department of Biosciences, College of Natural and Applied Sciences, Sokoine University of \\ Agriculture, PO Box 3038 Morogoro, Tanzania. \\ *Corresponding author. E-mails: erickmnyali14@gmail.com; smateru@sua.ac.tz \\ Received 15 Jun 2021, Revised 18 Oct 2021, Accepted 23 Oct 2021, Published Dec 2021
}

DOI: https://dx.doi.org/10.4314/tjs.v47i5.12

\begin{abstract}
A rapid increase in population and urban development has direct impacts on the natural environment of peri-urban areas of big cities, especially in the developing countries. This study examined land use and land cover changes (LULCC) of peri-urban areas of Kinondoni Municipality in Dar es Salaam city for the period between 1999 and 2019 and predicted future changes by 2039. The specific objectives were to; (i) map the spatial-temporal land use and cover changes (ii) analyze settlements (built-up areas) patterns and factors influencing their changes (iii) predict changes that might happen for the next two decades. LULCC for 1999 to 2019 were detected through Maximum Likelihood (ML) supervised classification techniques while Cellular Automata based on Artificial Neural Network (CA-ANN) model was used to predict future changes. Over the past two decades, $33.7 \%$ of vegetation has been lost due to increased settlements, as shown by linear development pattern of built-up areas, which has gained about $30 \%$ of other land covers. This study predicts that by 2039 , built-up areas will increase drastically to occupy $51.6 \%$, while vegetation and water cover will decrease to occupy $40.4 \%$ and $1.4 \%$, respectively. Without good planning strategies and land use policies, the control and management of the magnitude and patterns of peri-urban growth and sustainable management of natural and built environments in Tanzania will remain a challenge. This paper seeks to contribute to the body of knowledge required for evidence-based policy formulation and decision making to attain sustainable urbanization through setting suitable management plans for peri-urban areas of Tanzanian cities.
\end{abstract}

Keywords: Artificial Neural Network, Land use/cover changes, Maximum likelihood, Periurban, Remote sensing.

\section{Introduction}

Land use and land cover changes (LULCC) are regarded as major indicators in ecological and environmental changes and are keys for understanding the interactions between human and natural systems (Luo et al. 2008). LULCC can be referred to as human modifications of natural surfaces that cover the earth in a certain area, which might lead to new urban forms and structures (DiGiano et al. 2013). Peri-urban areas of major cities of developing countries are challenged by a complex pattern of unplanned urbanization and increased livelihood activities (Al-Bakri et al. 2013, Mkalawa 2016, Sumari et al. 2020). Urban growth, in this study referred to clustering of human activities (both economic and social) due to 
increased population, creates a huge pressure on natural environment and ecological resources of peri-urban areas (Lupala 2016). Spatial settlement patterns and land-use changes of many peri-urban areas of Tanzanian are largely driven by population pressures, availability of relatively cheaper built-land than in urban centers (Gwaleba 2018), livelihood activities such as agriculture (Kombe 2005), and household demand-driven factors such as fuelwood and construction materials (Berihun et al. 2019). These drivers may vary from one place to another depending on the socio-economic conditions of the neighboring city. According to Xu et al. (2019), small cities in African countries are characterized by a small urban land density (defined as the proportion of the built-up area to the buildable area), but the dispersion is higher than in medium and large cities. According to Dekker (2000), the urban population in developing countries is increasing due to rural-urban migration, and thus accelerates the establishment of new settlements in peri-urban areas. Thus, the dynamics of land use and cover changes in peri-urban areas of major cities in Tanzania, are mostly driven by population growth resulted from rural to urban migration and urban expansion (Nuhu 2019, Sumari et al. 2020, Wolff et al. 2021).

The rate of urbanization in major cities in Tanzania has increased from $6 \%$ in 1967 to $29 \%$ in 2012 (Todd et al. 2019), thus becoming one of the fastest urbanizing countries in sub-Saharan Africa. Dar es Salaam city holds the greatest proportion of the urban population in Tanzania with an estimated population of six million people and an annual growth rate of $2.5 \%$ (URT 2020). For the past two decades, natural environments in peri-urban areas in Dar es Salaam have been losing their ecological characters due to human encroachment for new settlements, increased livelihood activities such as sand mining, charcoal making, and pressure from urban expansion or newly established developmental projects for instance widening of new Bagamoyo road project (URT 2017).
Recent advancements in remote sensing and geospatial technologies have greatly come up with cost-effective techniques to monitor rapid LULC and can detect land-use change in time (Shao et al. 2021, Xu et al. 2019) and predict future LULCC by characterizing past trends of LULCC (Kamaraj and Rangarajan 2021, Manyama et al. 2020). When classifying satellite images, a supervised image classification techniques (maximum likelihood, minimum distance, spectral angle mapping, Mahalanobis distance) are mostly adopted as opposed to unsupervised techniques (clustering criteria, K-means clustering, Isodata clustering) because they have high ability to produce much more accurate LULCC results (Garosi et al. 2019, Msovu et al. 2020, Kitalika and Mlengule 2021). A variety of models have also been developed (machine learning model, cellular-based model, spatial-based model, agent-based approaches, hybrid approaches) to perform simulation-based prediction of future LULCC (Garosi et al. 2019). Among these models, Cellular Automata (CA) is a powerful approach for understanding land-use systems and their integral dynamics, especially when integrated with other tools, such as Artificial Neural Networks (ANNs) (Basse et al. 2014). This study, therefore, has deployed the use of the MOLUSCE plug-in which is a Quantum Geographical Information system (QGIS) based tool for predicting future LULCC. As described by Msovu et al. (2020) and Mzava et al. (2019), this plug-in is used to prepare a transition probability matrix using the CA$\mathrm{MC}$ approach and in the final simulation stage the CA model is used to predict future LULCC based on weights of evidence (WoE), logistic regression (LR), artificial neural networks (ANN), and multi-criteria evaluation (MCE) while validation is done using kappa statistics. The CA-ANNs work on what-if scenarios by integrating LULCC with spatial variables such as human population, digital elevation model and distance from the city centre (Charif et al. 2012). Therefore, CA-ANNs model is useful for planning and land-use change simulation studies. 
The significance of this study lies on an environmental perspective that it provides baseline data for understanding the current and predicted future rates of urbanization in peri-urban areas of Dar es Salaam city. For sustainable management of natural and built environments, these baseline data can help city planners and land use policy makers to set strategies and regulations that are crucial for the mitigation, control, and management of the magnitude and pattern of peri-urban growth in Tanzania. The objectives of this study were; (i) mapping spatial-temporal LULCC from 1999-2019, (ii) assessing settlements (built-up areas) patterns and factors influencing their changes and (iii) predicting changes that might happen for the next two decades (2019-2039) in Mbweni, Bunju, Kunduchi and Wazo wards of Kinondoni Municipality in Dar es Salaam as the case study.

\section{Materials and Methods Description of the study area}

Kinondoni Municipality is in the northwest of Dar es Salaam with an estimated area of 321 square kilometres (URT 2017), between $6.56^{\circ} \mathrm{S}, 39.12^{\circ} \mathrm{E}$ (in the north), $6.75^{\circ} \mathrm{S}, 39.28^{\circ} \mathrm{E}$ (in the east), $6.87^{\circ} \mathrm{S}, 39.11^{\circ} \mathrm{E}$ (in the south) and $6.78^{\circ} \mathrm{S}, 39.00^{\circ} \mathrm{E}$ (in the west). The municipal council is divided into twenty (20) wards which are bordered by the Indian Ocean to the north-east, Ilala, and Ubungo Districts to the south (URT 2017). According to URT (2018a), 61\% of manpower in Kinondoni municipality are in the private sectors responsible for waste collection, construction, education, healthcare, hospitality industry, nongovernmental organizations, trade, marketing, ICT, and transportation, $35 \%$ are selfemployed in the informal sectors (petty trades, entrepreneurs, livestock keepers, urban agriculture, fishing and vendors of various consumer goods and services), while only $4 \%$ of the population are government-employed workers in public sector. Kinondoni Municipality experiences a hot and humid climate throughout the year with an average temperature of $29{ }^{\circ} \mathrm{C}$. The hottest period is from October to March $\left(29^{\circ} \mathrm{C}\right)$, while it is relatively cool between May and August (25 ${ }^{\circ} \mathrm{C}$ ), with humidity ranging from $67 \%$ to $96 \%$ (URT 2018a). The municipality experiences an average annual rainfall of $1300 \mathrm{~mm}$ in bimodal rainfall patterns between April to October and November to March as influenced by the southwest and northeast monsoon winds, respectively (URT 2017).

This study was conducted in 4 wards of Kinondoni Municipality namely, Mbweni, Bunju, Kunduchi, and Wazo wards (Figure 1) with a total area of 137.615 square kilometres as representatives of the fast-developing periurban areas of Dar es Salaam City. These wards are rich in natural environments such as temporary rivers for instance river Tegeta which drains to the Indian Ocean, miombo woodland, and mangrove forests along the Indian Ocean shoreline (URT 2018a). The wards contain about 182,783 inhabitants, with an average of 4 habitats per household (URT 2020). 


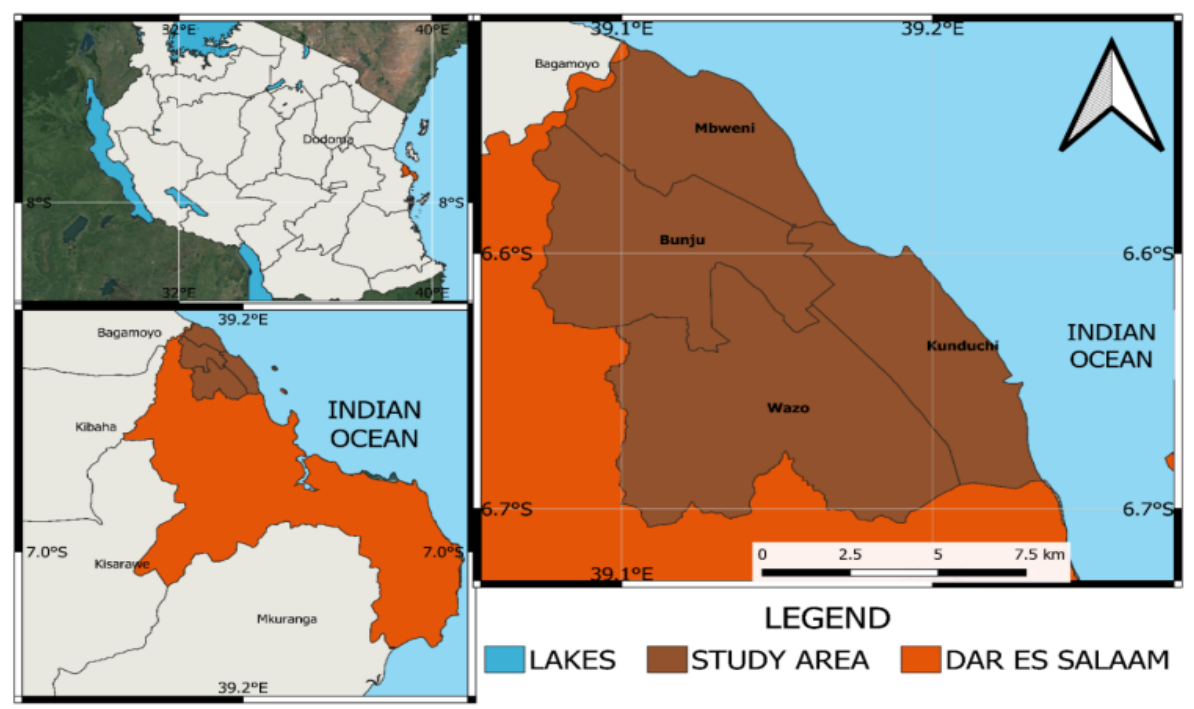

Figure 1: Maps showing the location of Dar es Salaam city and the study wards of the Kinondoni municipality.

Figure 2 summarizes the methods applied in this study to assess LULCC in Mbweni, Bunju, Wazo, and Kunduchi wards of
Kinondoni Municipality in Dar es Salaam City from 1999 to 2019 and prediction of future changes by 2039 .

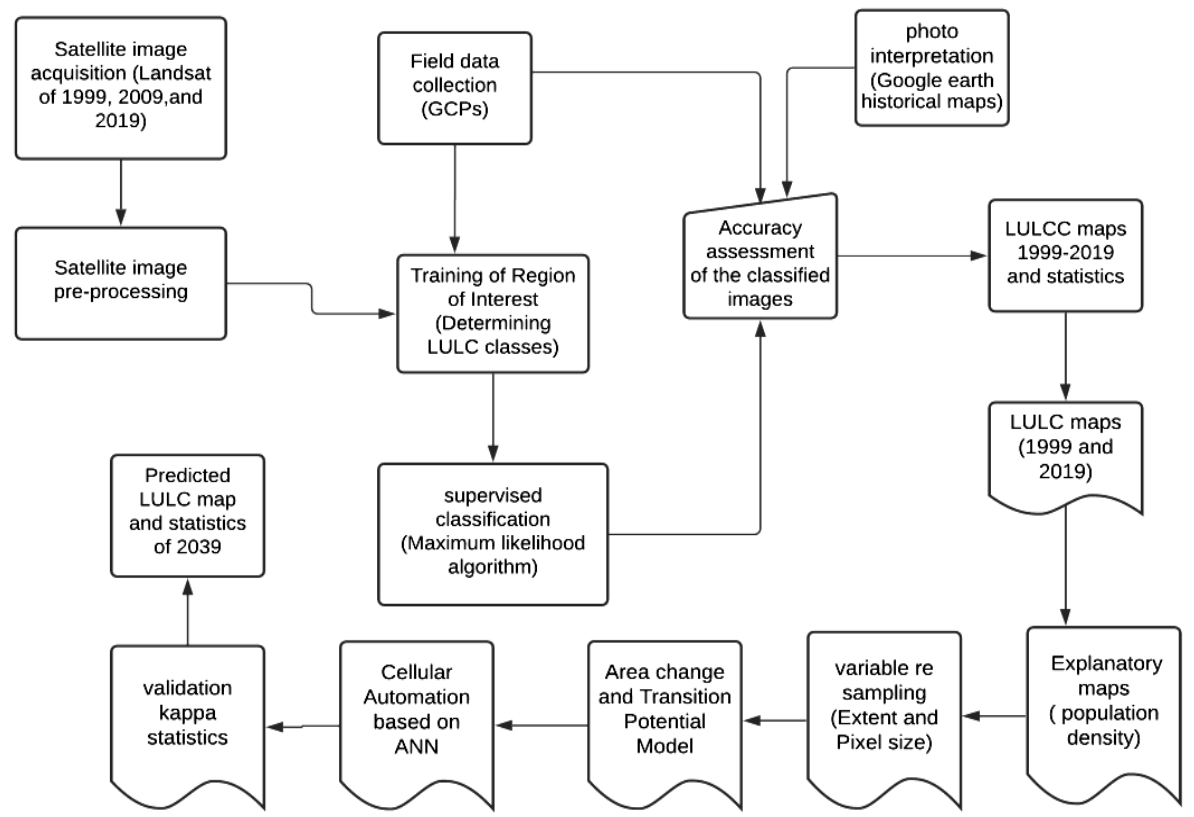

Figure 2: Schematic flow chart of applied methodology.

\section{Data acquisition and field survey}

In this study, ten years interval multitemporal satellite imageries from the USGS GLOVIS website (https://earthexplorer.usgs.gov/) were freely downloaded and used in image classification. Cloud-free satellite images of the same seasons (Table 1) were selected to avoid 
variation of the images during classification and to ease the detection of land use and land cover changes. One of the major concerns of Landsat 7 satellite products offered on the USGS website is the failure of Scan Line Corrector (SLC) which has resulted in data gaps in the imageries since May 13, 2003 (Wulder et al. 2008), thus the Landsat 7 imagery (Table 1) acquiesced in this study was not affected by the failure of SLC. Google Earth historical maps were also used together with on-site Ground Central Points (GCPs) collected using a Global Positioning System (GPS) device as LULC reference data to correctly train LULC classes for image classification and verify the correctness of the classified images as well. For prediction purposes, spatial variables raster data of population density for the years 1999 and 2019 were downloaded from Socioeconomic Data and Applications (SEDAC) website (Socioeconomic Data and Applications Center SEDAC (columbia.edu)).

\section{Satellite image pre-processing, analysis, and classification}

This study used a semi-automatic classification plug-in (SCP) in Quantum Geographical information system (QGIS) software (version 3.12.3) to perform satellite image pre-processing as well as classification. In the selection of bands to be used in the classification, thermal infrared bands were avoided because they have a different spatial resolution from other bands thus could affect the results of the classification (Congedo 2021). Pre-processing involved clipping of the satellite image using ward shapefiles of the study area from the website of Tanzania National Bureau of Statistics (http://www.nbs.go.tz). The clipped band images were then converted from Digital Number to surface reflectance. Dark Object
Subtraction (DOS1) algorithm was used to perform image-based atmospheric correction to improve the satellite images to be classified. Thereafter Regions of Interest (ROI) were created to define the land use and cover classes in the study wards. The histogram equalization technique was used to enhance the visual interpretation of satellite image bands for classification. From the virtual raster band set, Red, Green, and Blue (RGB) colour composites were used interchangeably together with field data collected to identify ROIs which represented LULC classes in the study area. Four major LULC classes identified for this study were; built-up areas (describing residential, industrial, commercial areas, man-made infrastructure, and settlements), vegetation (describing agriculture, crop, fallow land, forest areas, shrubs, conifers, and other green covers), water bodies (describing rivers, ponds, streams, coastal water zones, and various reservoirs), and bare land (describing area with exposed soil, un-vegetated lands, landfill sites, and actively excavated lands). For each LULC class, multiple ROIs were created and their spectral signatures were assessed to enhance the results of the classification.

After identifying major LULC classes and assessing their spectral signatures, the supervised classification (Maximum Likelihood (ML) algorithm) method was applied for the classification of the Landsat images as described by Richards and Jia (2006). ML algorithm calculates the probability distributions for the classes, related to the Bayesian theorem, estimating whether a pixel belongs to a certain land cover class. Before post-processing of the classification, multiple ROIs were reclassified to the LULC classes (vegetation, built-up areas, bare soil, and water).

Table 1: Downloaded satellite imagery for LULCC detection

\begin{tabular}{lllllll}
\hline Satellite & Sensor & Path/Row & Acquisition & Resolution & Season & Cloud cover \\
\hline Landsat 7 & ETM & $166 / 065$ & 30 July-1999 & $30 \mathrm{~m}$ & dry & $3 \%$ \\
Landsat 5 & TM & $166 / 065$ & 01 July-2009 & $30 \mathrm{~m}$ & dry & $5 \%$ \\
Landsat 8 & OLI-TRIS & $166 / 065$ & 27 June-2019 & $30 \mathrm{~m}$ & dry & $2 \%$ \\
\hline
\end{tabular}


Reports of the classified imagery that estimated the areas in hectares (ha) for each land use and land cover class from 1999 to 2019 were generated by post-processing tools in the SCP while estimation of the rate of changes for the different land cover use was computed based on simple image subtraction method (Lu et al. 2004) as adopted by Kashaigili and Majaliwa (2013).

(i) Area change $=($ Area of $\beta$ in year $2-$ Area of $\beta$ in year 1$)$

(ii) \% Area change

$=($ Area of $\beta$ in year $2-$ Area of $\beta$ in year 1$)$

(iii) Annual rate of change

$\div$ (total area in study area ) $\times 100 \%$

$=($ Area of $\beta$ in year $2-$ Area of $\beta$ in year 1$)$

$\div$ (years between year 1 and year 2$)$

Where; $\beta$ is a land cover or land use class in the study area

\section{Prediction of future land use and land cover changes}

Prediction of future LULCC in the study area was done using the Cellular Automata based on Artificial Neural Network (CAANN) model in Modules for Land Use Change Simulations Plug-in (MOLUSCE) version (3.0.13) in Quantum Geographical Information System software (version 2.18.5). The input variables for model training were; LULC classified images of 1999 and 2019 as the respective initial and final inputs. The spatial variables used to train the model were population density raster data of 1999 and 2019. These spatial variables were used as an independent variable, while LULC classified images were used as dependent variables which determined the LULCC projection to 2039 (i.e. 20 years projection). Evaluation by person's correlation method was used to examine the correlation among the spatial variable's factors in this study because this method gives information about the magnitude of the association as well as the direction of the relationship between spatial variables (Schober et al. 2018). The spatial variables were first re-sampled to match their geometries (extent and pixel size). Thereafter, by considering classified images of the initial year (1999) and the final year (2019), the LULCC map (1999-2019) and the transition matrix were produced. The LULCC map and transition matrix indicated the fraction of pixels changing from one type of LULC class to the next which were then used by the CAANN model for validation and simulating the 2039 LULC map.

\section{Accuracy assessment}

Accuracy assessment aimed to quantitatively assess how effectively the pixels were sampled into correct LULC classes. This study used the photointerpretation technique to assess the accuracy for classified images of 1999 and 2009. A total of 30 random points for each LULC class were clustered using the ISODATA algorithm which allows clustering of a different number of samples within a single LULC class. Thereafter, clustered random samples were photo interpreted using high spectral imagery from Google earth historical maps with 15 meters resolution and then reclassified to be used as reference raster for assessing the accuracy of classified images of 1999 and 2009. For the classified image of 2019, Ground Control Points (GCPs) collected during the field survey (Figure 3) were used as reference data to assess the accuracy of the classification. Overall accuracy and Kappa statistics as described by Costa et al. (2018), were the measures used to test the accuracy of the classified maps of 1999, 2009, and 2019. 


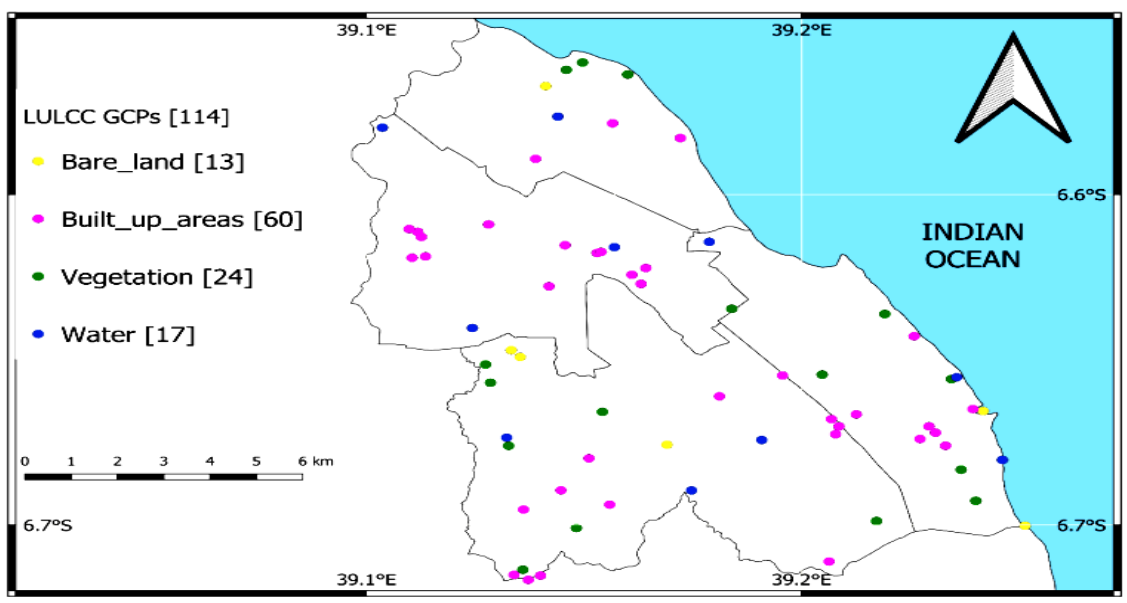

Figure 3: Map showing GCPs collected in the study area.

\section{Results and Discussions}

\section{Land use and land cover changes}

Ten years intervals of the land use land cover maps for the years 1999, 2009, and 2019 are presented in Figures $4 \mathrm{a}$ b and c. The accuracy of the classified maps of 1999 , 2009, and 2019 are as shown in Table 2. Both producer's accuracy (PA) and user's accuracy

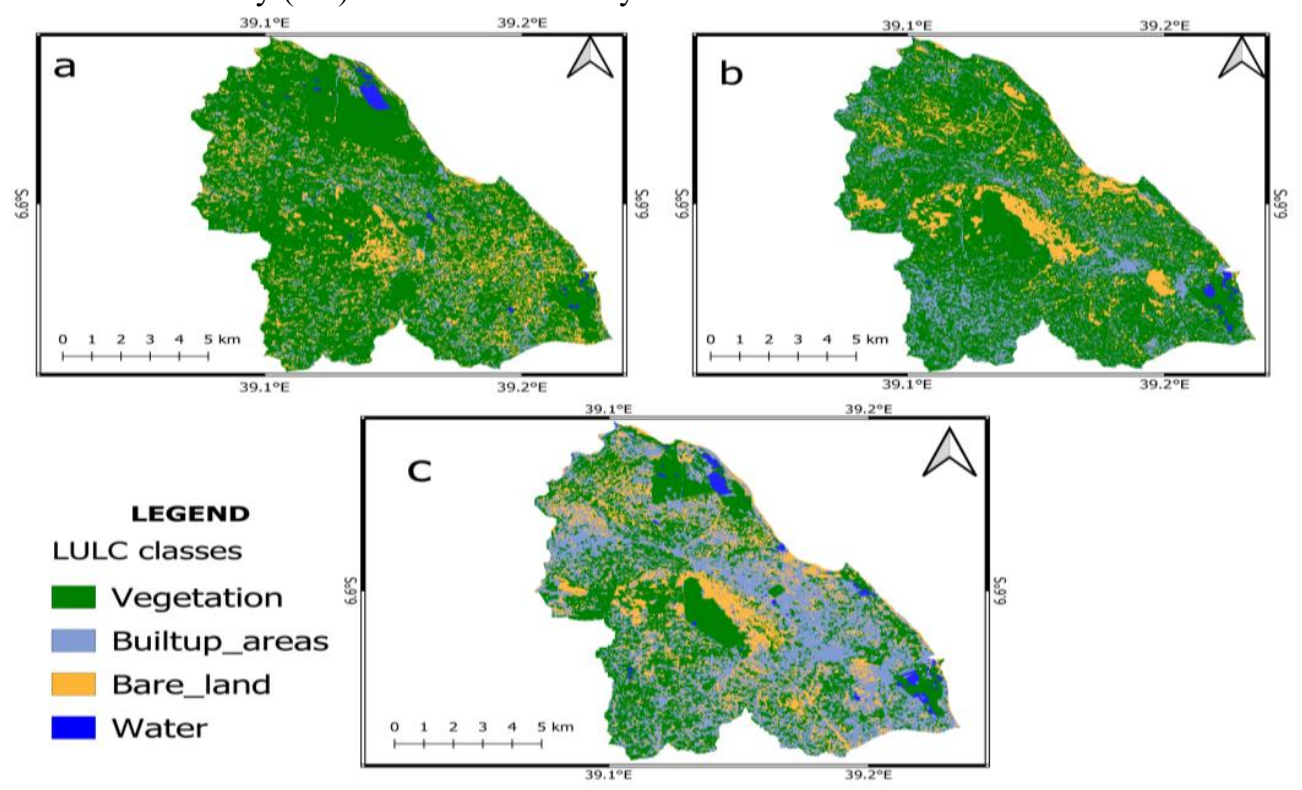

Figure 4: LULC maps of the study area for (a) 1999 (b) 2009 and (c) 2019.
(UA) of the LULC classes are indicated with overall classification accuracies and their corresponding Kappa statistics. With kappa statistics of $0.89,0.88$, and 0.93 for LULC maps of 1999, 2009, and 2019 respectively, the produced maps can be rated almost perfect. 
Table 2: $\quad$ Producer's Accuracy (PA) and User's Accuracy (UA) of land use and land cover changes 1999-2019.

\begin{tabular}{llcccccc}
\hline \multirow{2}{*}{ LULC classes } & \multicolumn{2}{c}{1999} & \multicolumn{2}{c}{2009} & \multicolumn{2}{c}{2019} \\
\cline { 2 - 8 } & PA & UA & UA & PA & UA & PA \\
\hline Vegetation & 92.3 & & 92.0 & 90.3 & 94.5 & 93.4 & 92.2 \\
Built-up areas & 93.3 & & 89.2 & 89.3 & 90.4 & 94.3 & 92.4 \\
Bare land & 92.4 & & 88.3 & 86.5 & 88.4 & 92.7 & 90.6 \\
Water & 84.8 & & 87.9 & 89.4 & 86.1 & 88.5 & 89.5 \\
\hline Overall accuracy & & 90.2 & \multicolumn{2}{c}{89.3} & & \multicolumn{2}{c}{95.1} \\
Kappa statistics & & 0.89 & \multicolumn{2}{c}{0.88} & & \multicolumn{2}{c}{0.93} \\
\hline
\end{tabular}

Table 3 presents change detection statistics of LULC classes in Mbweni, Bunju, Kunduchi, and Wazo wards from 1999 to 2019. Area change in hectares (ha), percentage area change (\%) and annual rate of change in hectares per year (ha/year) were computed according to equation (i), (ii) and (iii) respectively. The increased and decreased amount of change in hectares is shown by positive (+) and negative (-) signs, respectively.

Mbweni, Bunju, Kunduchi, and Wazo wards have witnessed considerable changes in land use and land cover during the last two decades. Table 3 indicates that for the period between 1999 and 2009, vegetation cover decreased from $10,246.1$ ha $(74.5 \%)$ to 9,597.1 ha (69.7\%), indicating a $4.8 \%$ loss while built-up areas increased from 1,261.2 ha $(9.2 \%)$ in 1999 to 2380.1 ha $(17.3 \%)$ in 2009 , indicating an increase of $8.1 \%$, equivalent to an annual gain of 301.1 ha per year. Tanzanian census reports showed that the population of Kinondoni municipality rose from $1,083,913$ in 2002 to $1,775,049$ in 2012 (URT 2003, 2013), which was equivalent to $43 \%$ (2002) and 40\% (2012) of the total population in Dar es Salaam City and also a higher annual population growth rate of $5.6 \%$ compared to $4.3 \%$ between 1988 and 2002. Therefore, the observed LULCC were most likely due to more people searching for bare land to establish settlements and socioeconomic activities for livelihood, which contributed to the decrease in vegetation cover. Built-up areas showed a scattered pattern in four wards (Figure 4a) but ten years later, a linear pattern was observed (Figure 4b). According to URT (2017), this spatial pattern of LULCC in Kunduchi, Bunju,
Wazo, and Mbweni wards was first influenced by limited land for establishing new settlements in urban areas, which results in urban-peri-urban migration then catalyzed by good road networks (construction of the new Bagamoyo road) and other public infrastructural services such as electricity and water. In the window period 1999 and 2009, bare land decreased from $2,069.6$ ha $(15 \%)$ to $1,677.5$ ha $(12.2 \%)$ indicating a $2.8 \%$ loss while water cover was lost by $0.5 \%$ (from 184.6 ha $(1.3 \%)$ to 106.7 ha $(0.8 \%)$. Therefore, this study shows that built-up areas have negatively affected both water and bare land classes for the period 1999-2009, which is in line with a study by Mbonile and Kivelia (2008) that showed built-up areas increasingly interfering with mangrove and river ecosystems in Boko, Bunju, and Ununio villages of Kinondoni Municipality.

Between 2009 to 2019 built-up areas, bare lands, and water cover had gained by $21.9 \%$, $6 \%$, and $1 \%$, respectively, while vegetation cover was lost by $28.9 \%$. Built-up areas increased drastically from $2,380.1$ ha $(17.3 \%)$ in 2009 to $5,390.6$ ha $(39.2 \%)$ in 2019 . The increase of built up areas can easily be associated with urban growth due to increase in population in Dar es Salaam city that elevates demands for land thus creating pressure in the natural environment of the peri-urban areas. Also, the positive change of bare land in this window period is the result of the population pressure resulting in the demanded land for human-related activities for instance agriculture and settlements, which have also positively impacted water bodies. LULC gain and loss for the window periods 1999-2009 and 2009-2019 are presented in Figure 5. From 1999 to 2019, a 
significant difference is observed between LULC classes $(p \leq 0.05)$. In the window period 1999 to 2009, the rate of LULCC especially the built-up areas, in the study wards were somewhat dormant. According to Mbonile (2013), limited public services such as infrastructures and other important services including water and hospitals directly limited urban expansion from Dar es Salaam city centre. However, built-up areas increased rapidly and linearly from the period 2009 to 2019, which is causally linked to the widening of the new Bagamoyo road that passes through Kunduchi and Bunju wards to Bagamoyo in the Coastal region. For similar reasons drastic decrease of vegetation, is also justified by an increase of 82.6 ha per year of bare land describing areas with exposed soil, un-vegetated lands, sand mining areas, landfill sites, and actively excavated lands in Wazo cement factory areas from 2009 to 2019.

The transition area matrix in Table 4 shows changes of one land use and land cover class to another at a temporal scale between 1999 and 2019. Numbers in brackets indicate the area of land use and land cover class pixels that were unchanged.

The transformation from vegetation to built-up areas was observed to be the major land cover transition from 1999 to 2019. Table 4 shows that, for the past 20 years, about 3804.4 ha of vegetation cover and 1002.8 ha of bare land were converted to built-up areas from 1999 to 2019. These results indicate uneven transitions between vegetation and built-up areas at a ratio of approximately 10:1, implying increase in population and livelihood activities. As reported by Mzava et al. (2019). Rapid population increase and the influx of urban population, has a negative impact on the natural vegetation as more people will search for a much cheaper land and accommodation in the periphery of the city. Therefore, it is obvious that for the period 1999 to 2019, rapid loss of vegetation was most likely to occur due to population surge. Figure 5 addresses the net change of each LULC class in two window periods, showing a significant loss of vegetation and gain of built-up areas. Bare land and water had insubstantial changes showing both increase and decrease trends in the window periods. Rapid increase and decrease of built-up areas and vegetation classes may be the cause of fluctuations in bare land and water classes. 
Tanz. J. Sci. Vol. 47(5) 2021

Table 3: Land use/cover area distribution between 1999 and 2019

\begin{tabular}{|c|c|c|c|c|c|c|c|c|c|c|c|c|}
\hline \multicolumn{7}{|l|}{ LULC classes } & \multicolumn{3}{|c|}{ Changes between 1999-2009 } & \multicolumn{3}{|c|}{ Changes between 2009-2019 } \\
\hline & $\begin{array}{l}1999 \\
\text { (ha) }\end{array}$ & $\%$ & $\begin{array}{l}2009 \\
\text { (ha) }\end{array}$ & $\%$ & $\begin{array}{l}2019 \\
\text { (ha) }\end{array}$ & $\%$ & $\begin{array}{l}\text { Area } \\
\text { change } \\
\text { (ha) }\end{array}$ & $\begin{array}{l}\text { Area } \\
\text { chan } \\
\text { ge } \\
(\%) \\
\end{array}$ & $\begin{array}{l}\text { Annual } \\
\text { rate } \\
\text { change } \\
\text { (ha/year) }\end{array}$ & $\begin{array}{l}\text { Area } \\
\text { change } \\
\text { (ha) }\end{array}$ & $\begin{array}{l}\text { Area } \\
\text { chan } \\
\text { ge } \\
(\%) \\
\end{array}$ & $\begin{array}{l}\text { Annual } \\
\text { rate } \\
\text { change } \\
\text { (ha/year) }\end{array}$ \\
\hline Vegetation & 10246.1 & 74.5 & 9597.1 & 69.7 & 5617.4 & 40.8 & -649 & -4.8 & -64.9 & -3979.7 & -28.9 & -398.0 \\
\hline Built-up areas & 1261.2 & 9.2 & 2380.1 & 17.3 & 5390.6 & 39.2 & 1118.9 & 8.1 & 111.9 & 3010.5 & 21.9 & 301.1 \\
\hline Bare land & 2069.6 & 15.0 & 1677.5 & 12.2 & 2503.9 & 18.2 & -392.1 & -2.8 & -39.2 & 826.4 & 6.0 & 82.6 \\
\hline
\end{tabular}

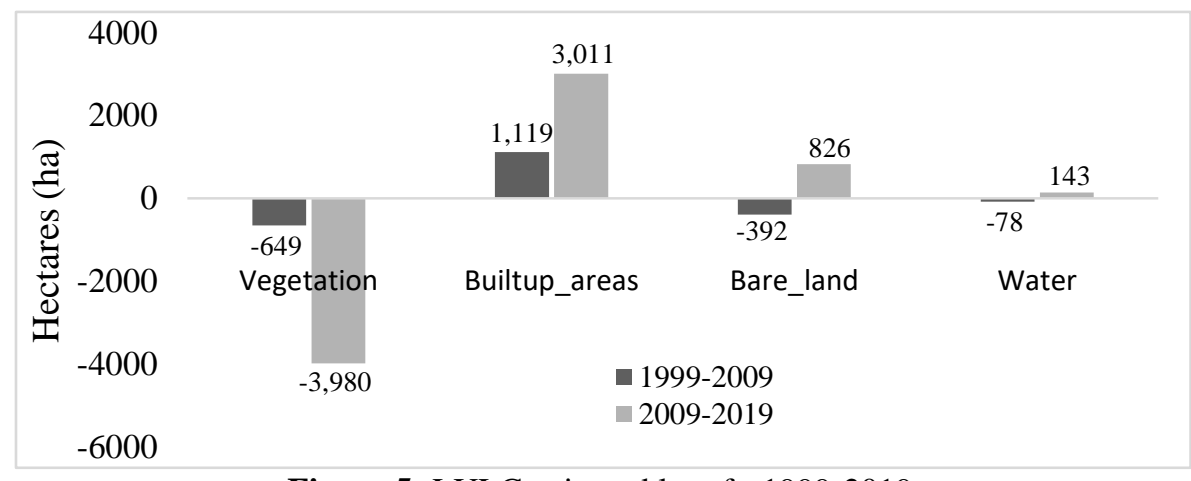

Figure 5: LULC gain and loss for1999-2019. 
Land use and land cover prediction (2019. 2039)

Figure $6(a, b)$ presents maps of the spatial variables used independently to project future changes. The spatial variables showed a positive Pearson correction value of 0.77 describing a significant and positive relationship of the variables. Twenty years projection LULCC map is presented in Figure 7. Overall kappa coefficient value of 0.67 during model training and prediction showed good prediction of the results.

The transition probability matrix in Table 5 expresses the likelihood that an area of a given class will change to any other class or stay the same in the next 20 years period. Table 5 shows that in 2039, 37.1\% of the current vegetation cover is expected to change to built-up areas while $23.7 \%$ of the built-up land and $17.1 \%$ of vegetation land might change to bare land by 2039 . The model significantly predicts a surge of change from bare land to built-up areas in 2039 by $48.5 \%$. Table 5 also alerts that in 2039 insignificant probability changes will be expected for water, whereby $0.4 \%$ of water areas will be bare land, $0.1 \%$ will be built-up areas and only about $1.1 \%$ will be covered with vegetation. The prediction shows that about $70.7 \%$ of the areas covered by water in 2019 will remain the same in 2039, indicating protected estuaries. Generally, from the probabilities in Table 5, drastic increases and decreases are expected for built-up areas and bare land respectively while insignificant changes for water and vegetation classes are expected.

Table 4: LULCC transition area matrix from 1999 to 2019 in hectares (ha)

\begin{tabular}{lccccc}
\hline & \multicolumn{5}{c}{1999} \\
\cline { 2 - 6 } 2019 & Vegetation & Built-up areas & Bare land & Water & Total \\
\hline Vegetation & $(4580.7)$ & 396.9 & 608.4 & 31.4 & 5617.4 \\
Built-up areas & 3804.4 & $(564.3)$ & 1002.8 & 19.2 & 5390.6 \\
Bare land & 1751.1 & 298.7 & $(450.6)$ & 3.4 & 2503.9 \\
Water & 110.0 & 1.3 & 7.7 & $(130.6)$ & 249.6 \\
total & 10246.2 & 1261.2 & 2069.5 & 184.6 & 13761.5 \\
\hline
\end{tabular}
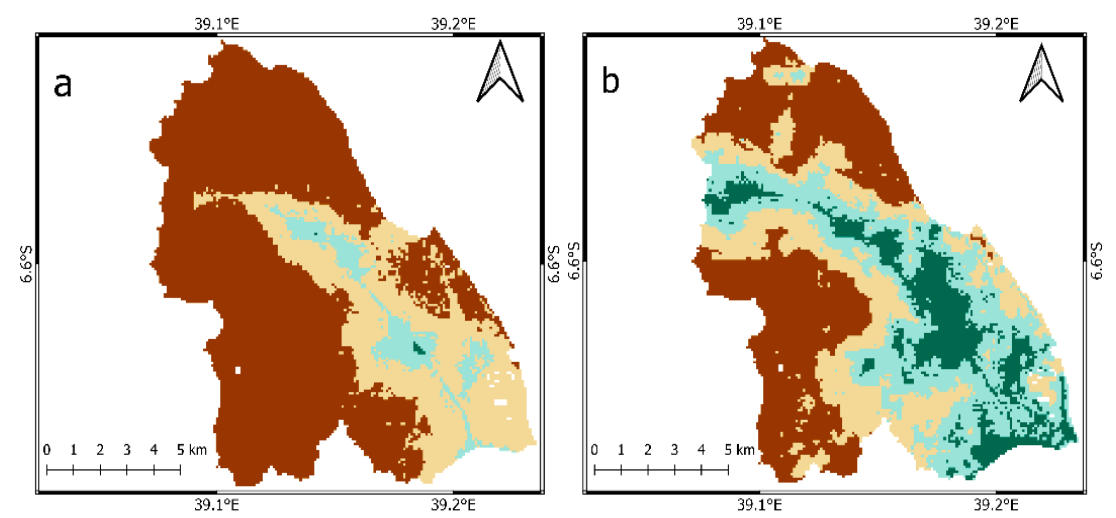

LEGEND

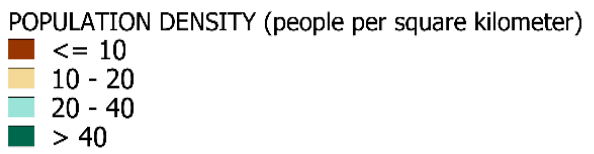

Figure 6: Maps of spatial variables in the study area for (a) 1999 (b) 2019. 
Table 5: Transition probability matrix for various land use and cover types

\begin{tabular}{lllll}
\hline \multirow{2}{*}{2019} & \multicolumn{4}{c}{ Probability of a cell to change in 2039 } \\
\cline { 2 - 5 } & Vegetation & Built-up areas & Bare land & Water \\
\hline Vegetation & 0.447 & 0.371 & 0.171 & 0.011 \\
Built-up areas & 0.315 & 0.477 & 0.237 & 0.001 \\
Bare land & 0.294 & 0.485 & 0.218 & 0.004 \\
Water & 0.170 & 0.094 & 0.019 & 0.707 \\
\hline
\end{tabular}

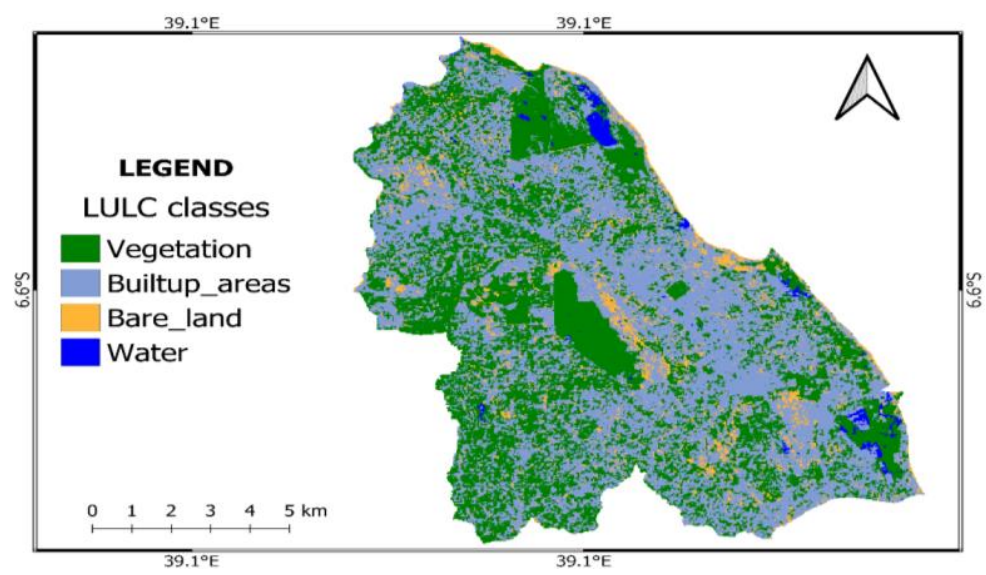

Figure 7: Predicted LULC map for the year 2039 based on the CA-ANN model.

The relationships of LULC classes in the transition probability matrix in Table 5 were used to quantify the future changes in the temporal range of twenty years. Area changes in hectares (ha) and their percentages (\%), as well as change detection estimation for every predicted class, are presented in Table 6. Figure 8 presents LULC gain and loss, increased and decreased amount of change in hectares (ha) are shown by positive (+) and negative (-) signs, respectively.

Prediction of land use and land cover changes from 2019-2039 in the Table 6 revealed that built-up will dominate with an increased rate of 85.5 ha per year, which is equivalent to 7101.1 ha $(51.6 \%)$ of the total land in Mbweni, Bunju, Kunduchi and Wazo wards in 2039. Vegetation will decrease insubstantially at a rate of 2.9 ha per year equivalent to 5560.2 ha $(40.4 \%)$ while bare soil will decrease substantially from 2503.9 ha $(18.2 \%)$ in 2019 to 908.1 ha $(6.6 \%)$ in 2039. The area covered by water bodies will decrease at a rate of 2.9 ha per year which is equivalent to 192.2 ha $(1.4 \%)$ by 2039 . The transition of vegetation class indicates agriculture, crop, fallow land, forest areas, shrubs, conifers, and other green covers will be replaced by built-up areas (residential, industrial, commercial areas and man-made infrastructure). According to National Bureau of Statistics (NBS) projection reports, the population of Dar es Salaam city is expected to reach $13,383,362$ by 2035 indicating a population growth of 547,374 (4.26\%) (URT 2018b).

This surge in population growth describes the dominance of built-up areas in the periurban areas of the city by 2039 . According to Halloran and Magid (2013), the city's expansion of the built-up areas can be associated with various environmental challenges and socio-economic challenges such as floods, pollution, and poor access to basic needs. 


\section{Acknowledgement}

The authors acknowledge the critical comments of the three anonymous reviewers that have helped to improve this article.

\section{References}

Al-Bakri JT, Duqqah M and Brewer T 2013 Application of remote sensing and GIS for modeling and assessment of land use/cover change in Amman/Jordan. J. Geog. Info. Sys. 5(5): 509-519.

Basse RM, Omrani H, Charif O, Gerber P and Bódis K 2014 Land use changes modelling using advanced methods: Cellular automata and artificial neural networks. The spatial and explicit representations of land cover dynamics at the cross-border region scale. Appl. Geog. 53: 160-171.

Berihun ML, Tsunekawa A, Haregeweyn N, Meshesha DT, Adgo E, Tsubo M, Adgoe E, Tsuboc M, Masunaga T, Fenta AA, Sultan D and Yibeltal M 2019 Exploring land use/land cover changes, drivers and their implications in contrasting agro-ecological environments of Ethiopia. Land Use Policy 87:104052.

Charif O, Omrani H, and Basse RM 2012 Cellular automata based on artificial neural network for simulating land use changes. In Society for Computer Simulation International (2012) ANSS 12-Proceedings of the $45^{\text {th }}$ Annual Simulation Symposium March 26-30, 2012, San Diego CA United States (pp. 1-9).

Congedo L 2021 Semi-automatic classification plugin: A Python tool for the download and processing of remote sensing images in QGIS. J. Open Sour. Soft. 6(64): 3172.

Costa H, Foody GM, and Boyd DS 2018 Supervised methods of image segmentation accuracy assessment in land cover mapping. Remote Sens. Environ. 205: 338-351.

Dekker R 2000 Monitoring the urbanization of Dar es Salaam using ERSSAR data. Int. Arch. Photog. Rem. Sens. 33 (B1; Part 1): 62-69.

DiGiano M, Ellis E and Keys E 2013 Changing landscapes for forest commons: linking land tenure with forest cover change following Mexico's 1992 Agrarian Counter-Reforms. Human Ecol. 41(5): 707-723.

Garosi Y, Sheklabadi M, Conoscenti C, Pourghasemi HR, and Van Oost K 2019 Assessing the performance of GIS-based machine learning models with different accuracy measures for determining susceptibility to gully erosion. Sci. Total Environ. 664: 1117-1132.

Gwaleba MJ 2018 Urban growth in Tanzania: Exploring challenges, opportunities, and management. Int. J. Soc. Sci. Stud. 6: 47-60.

Halloran A and Magid J 2013 Planning the unplanned: incorporating agriculture as an urban land use into the Dar es Salaam master plan and beyond. Environ. Urban. 25(2): 541-558.

Kashaigili JJ and Majaliwa AM 2013 Implications of land use and land cover changes on hydrological regimes of the Malagarasi River, Tanzania. J. Agri. Sci. Appl. 2(1): 45-50.

Kitalika I and Mlengule D 2021 Assessing 30 years of land use dynamics in Usangu Catchment, Tanzania. J. Geogr. Assoc. Tanz. 41(1): 1-18.

Kombe WJ 2005 Land use dynamics in periurban areas and their implications on the urban growth and form: the case of Dar es Salaam, Tanzania. Habitat Int. 29(1): 113135.

Lu D, Mausel P, Brondizio E and Moran E 2004 Change detection techniques. Int. J. Remote Sens. 25(12): 2365-2401.

Luo GP, Zhou CH, Chen X, and Li Y 2008 A methodology of characterizing status and trend of land changes in oases: A case study of Sangong River watershed, Xinjiang, China. J. Environ. Manage. 88(4): 775-783.

Lupala JM 2016 The effects of peri-urbanization on Pugu and Kazimzumbwi forest reserves, Dar es Salaam, Tanzania. Int. J. Phys. Hum. Geo. 3(2): 49-92.

Manyama MT, Nahonyo CL, and Hepelwa AS 2020 Analysis of the impact of built environment on coastline ecosystem services and values. East Afr. J. Environ. Nat. Resour. 2(2): 44-63.

Mbonile MJ 2013 Migration and micro-level socio-economic development of peri-urban villages in Kinondoni District, Tanzania. $J$. Geo. Assoc. Tanz. 34: 42-62.

Mbonile MJ and Kivelia J 2008 Population, environment and development in Kinondoni District, Dar es Salaam. Geo. J. 174(2): 169175.

Mkalawa CC 2016 Analyzing Dar es Salaam urban change and its spatial pattern. Int. J. Urban Plan. Transp. 31(1): 1138-1150. 
Msovu UE, Mulungu DM, Nobert JK and Mahoo H 2020 Land use/cover change and their impacts on stream flow in Kikuletwa Catchment of Pangani River Basin, Tanzania. Tanz. J. Eng. Technol. 38(2): 171192.

Mzava P, Nobert J and Valimba P 2019 Land cover change detection in the urban catchments of Dar es Salaam, Tanzania using remote sensing and GIS techniques. Tanz. J. Sci. 45(3): 315-329.

Nuhu S 2019 Land-access systems in peri-urban areas in Tanzania: Perspectives from Actors. Int. J. Urban Sustain. Dev. 11(2): 189-202.

Kamaraj M and Rangarajan S 2021 Predicting the future land use and land cover changes for Bhavani Basin, Tamil Nadu, India Using QGIS MOLUSCE Plugin. Environ. Sci. Policy Res. 28: 1-13.

Richards JA and Jia X 2006 Image Classification Methodologies. In: RemoteSensing Digital Image Analysis. Springer, Berlin, Heidelberg. pp 295-332.

Schober P, Boer C, and Schwarte LA 2018 Correlation coefficients: appropriate use and interpretation. Anesthes Analges. 126(5): 1763-1768.

Shao Z, Sumari NS, Portnov A, Ujoh F, Musakwa W, and Mandela PJ 2021Urban sprawl and its impact on sustainable urban development: a combination of remote sensing and social media data. Geo-Spat. Info. Sci. 24(2): 241-255.

Sumari NS, Cobbinah PB, Ujoh F and Xu G 2020 On the absurdity of rapid urbanization: Spatio-temporal analysis of land-use changes in Morogoro, Tanzania. Cities. 107: 102876.

Todd G, Msuya I, Levira F and Moshi I 2019 City Profile: Dar es Salaam, Tanzania. Environ. Urban. ASIA. 10(2): 193-215.

URT (United Republic of Tanzania) 2003 The 2002 Population and Housing Census: Population Distribution by Administrative Areas. National Bureau of Statistics, Ministry of Finance, Dar es Salaam; and Office of the Chief Government Statistician, Ministry of State, President's Office, State
House and Good Governance Zanzibar, Government printer; Dar es Salaam.

URT 2013 The 2012 Population and Housing Census: Population Distribution by Administrative Areas. National Bureau of Statistics, Ministry of Finance, Dar es Salaam; and Office of the Chief Government Statistician, Ministry of State, President's Office, State House and Good Governance Zanzibar, Government printer; Dar es Salaam.

URT 2017 Kinondoni Municipal Profile -2017, Prime Minister's Office, Regional Administration and Local Government, Dar es Salaam, Tanzania.

URT 2018a Kinondoni Municipal Profile-2018, Prime Minister's Office, Regional Administration and Local Government, Dar es Salaam, Tanzania.

URT 2018b The National Population Projections (2013-2035): National Bureau of Statistics, Ministry of Finance, Dar es Salaam; and Office of the Chief Government Statistician, Ministry of State, President's Office, State House and Good Governance Zanzibar, Government printer; Dar es Salaam.

URT 2020 Tanzania in Figures 2019, National Bureau of Statistics, Dodoma, Tanzania.

Wolff S, Mdemu MV and Lakes T 2021 Defining the peri-urban: a multidimensional characterization of spatio-temporal land use along an urban-rural gradient in Dar es Salaam, Tanzania. Land 10(2): 177.

Wulder MA, Ortlepp SM, White JC and Maxwell S 2008 Evaluation of Landsat-7 SLC-off image products for forest change detection. Canad. J. Rem. Sens. 34(2): 9399.

Xu G, Dong T, Cobbinah PB, Jiao L, Sumari NS, Chai B, and Liu Y 2019 Urban expansion and form changes across African cities with a global outlook: Spatiotemporal analysis of urban land densities. J. Clean. Prod. 224: 802-810. 